\title{
Isolated Glucocorticoid Deficiency
}

National Cancer Institute

\section{Source}

National Cancer Institute. Isolated Glucocorticoid Deficiency. NCI Thesaurus. Code

C120446.

Abnormally low or absent production of glucocorticoids, characterized by

unresponsiveness to adrenocorticotropic hormone. It is hereditary and potentially lethal. 